\title{
Impresso ou digital? As práticas de ler textos no papel e na tela
}

\section{Printed or digital? The practice of reading texts on paper}

\author{
and on screen
}

\section{Maria da Guia Silva*}

\begin{abstract}
RESUMO: Neste artigo, apresentamos algumas declarações sobre as práticas de ler textos no papel e na tela sob a visão de graduandos do Bacharelado em Ciências e Tecnologia da Universidade Federal do Rio Grande do Norte (BCT/UFRN). Esses graduandos cursaram o componente curricular Práticas de Leitura e Escrita II (PLE-II), no primeiro semestre de 2011. Nele, pretendemos explorar, entre outros, a polêmica sobre o futuro do mercado editorial que passa pelos seguintes questionamentos: os livros impressos resistirão às novas tecnologias? Os e-books suplantarão os livros impressos? É possível a coexistência de livros impressos e livros digitais? Para tanto, no decorrer desse estudo, trazemos para análise o que dizem seis desses graduandos nas entrevistas semiestruturadas e nos artigos de opinião que eles produziram para contribuir com esse debate. Esse material selecionado para este estudo faz parte do corpus da pesquisa ${ }^{1}$ concluída com esses colaboradores. A análise desses dados seguirá os pressupostos teórico-metodológicos da concepção de língua(gem) de Bakhtin (2009), dos estudos de letramento como prática social (KLEIMAN, 1995, 2005; OLIVEIRA; KLEIMAN, 2008), dos estudos sobre o letramento digital (XAVIER, 2002; COSCARELLI; RIBEIRO, 2007). Os resultados da análise empreendida apontam-nos para uma multiplicidade de práticas de leitura/escrita de textos impressos e digitais desenvolvidas por graduandos do BCT devido à coexistência da modalidade impressa e da que decorre dos novos dispositivos móveis.
\end{abstract}

PALAVRAS-CHAVE: Textos impressos. Textos digitais. Letramento digital.

ABSTRACT: This article presents some statements about the practices of reading texts on paper and on screen in view of the undergraduate Bachelor of Science and Technology, Federal University of Rio Grande do Norte (BCT/UFRN). These graduates

\footnotetext{
* Mestra pelo Programa de Pós-graduação em Estudos da Linguagem da Universidade Federal do Rio grande do Norte. Professora de Português do Ensino Médio, vinculada à Secretaria Estadual de Educação do Rio Grande do Norte. E-mail: guia.silva19@hotmail.com.

${ }^{1}$ Este estudo insere-se na pesquisa de mestrado na área de Linguística Aplicada concluída no início de 2013 e intitulada "O leitor universitário e a construção das práticas de ler textos impressos e digitais", sob a orientação da Professora Doutora Glícia Azevedo Tinoco (PPGEL/ECT/UFRN), no Programa de Pós-Graduação em Estudos da Linguagem da UFRN.
} 
attended the curricular component Practice Reading and Writing II (PLE- II) in the first half of 2011. In him, we intend to explore, among other things, the controversy over the future of publishing that goes through the following questions: Printed books resist the new technologies? The e-books will supersede printed books? It is possible the coexistence of printed books and digital books? To do so, during this article, we bring the analysis to say six of undergraduates in semi-structured interviews and opinion articles they produced to contribute to this debate. The materials selected for this study is part of the corpus of research completed with these reviewers. The analysis of these data follow the theoretical and methodological assumptions of the design language (gem) Bakhtin (2009), studies of literacy as social practice (KLEIMAN 1995, 2005, OLIVEIRA; KLEIMAN, 2008), studies on digital literacy (XAVIER, 2002; COSCARELLI; RIBEIRO, 2007). The results of this analysis point us to a multiplicity of practices of reading/writing of printed and digital texts developed by graduating BCT due to the coexistence of the printed form and that stems from new mobile devices.

KEYWORDS: Printed texts. Digital texts. Digital literacy.

\section{Introdução}

Nos últimos anos, a chegada do computador e da internet tem alterado diversas atividades da vida contemporânea. Tais mudanças também têm alcançado o modo de agir do espaço educacional, o processo de ensino e aprendizagem. Isso levou alguns estudiosos da educação, dentre eles, (XAVIER, 2002; COSCARELLI; RIBEIRO, 2007), a refletirem e a pesquisarem sobre as consequências de novas tecnologias em novas práticas sociais e em novos usos da linguagem na sociedade.

A cada dia, cresce o número de pessoas que adquirem e utilizam esses novos dispositivos tecnológicos (celular, computador, smartphone, cartão eletrônico) na vida social. Isso tem exigido dos consumidores mudanças no que diz respeito à aprendizagem, ao comportamento e ao entendimento peculiar. Por essa razão, alguns estudiosos passaram a discutir sobre o surgimento de novos modos de ler e escrever, um novo paradigma ou novas práticas de letramento: o letramento digital (XAVIER, 2002).

Sobre letramento digital, Xavier (2002) considera a necessidade de cada indivíduo dominar um conjunto de informações e habilidades mentais que devem ser trabalhadas pelas instituições de ensino o mais rápido possível. No entanto, tais instituições devem capacitar com urgência os alunos para que cidadãos possam ser agentes com autonomia também em relação às 
possibilidades que o computador e a internet oferecem. Repensar o ensino e o uso dessas novas tecnologias nas salas de aula, portanto, pode possibilitar a inclusão desses cidadãos neste universo cada vez mais cercado por máquinas digitais.

Organizar este artigo significa reconfigurar esses novos modos de ler e de escrever. Isso porque o objetivo desse estudo é refletir sobre as práticas de ler textos impressos e digitais na visão de graduandos do Bacharelado em Ciências e Tecnologia da Universidade Federal do Rio Grande do Norte (BCT/UFRN). Optamos por esses colaboradores pelo fato de estarem em uma unidade acadêmica que se volta, principalmente, para as áreas exatas e de engenharias. Buscamos também explorar, entre outros, a polêmica sobre 0 futuro do mercado editorial que passa pelos seguintes questionamentos: os livros impressos resistirão às novas tecnologias? Os e-books suplantarão os livros impressos? É possível a coexistência de livros impressos e livros digitais?

\section{Procedimentos metodológicos}

O corpus deste artigo advém dos instrumentos utilizados para a pesquisa de mestrado concluída com os colaboradores citados anteriormente. Para tanto, trazemos o que dizem seis desses graduandos sobre as práticas de leitura de textos no papel ou na tela em artigos de opinião por eles produzidos e nas entrevistas semiestruturadas. Estes recortes foram selecionados conforme os objetivos aqui propostos.

O procedimento metodológico foi o seguinte: 1) selecionamos seis artigos de opinião; 2) retiramos alguns recortes deles; 3) separamos algumas transcrições da entrevista semiestruturada, investigando, na materialidade linguística deles, elementos para que possamos compreender o posicionamento dos graduandos sobre o que eles dizem acerca de práticas de leitura/escrita que desenvolvem.

Ressaltamos que o artigo de opinião foi a questão discursiva da avaliação culminativa aplicada aos graduandos do BCT que cursaram PLE-II, no mês de abril de 2011. Além de artigos, os graduandos também podiam se 
posicionar através de carta argumentativa sobre a organização do acervo da biblioteca setorial da ECT.

Nessas produções, os graduandos emitiram sua opinião sobre qual seria a melhor escolha para compor esse acervo, se a publicação de texto no papel ou na tela. Tais produções textuais não foram produzidas para fins de investigação, mas foram direcionadas ao corpus da pesquisa por considerá-las relevantes, isto é, porque nos sinalizavam possíveis respostas às perguntas de nossa pesquisa. Nossa pesquisa contou com a colaboração de quinze jovens universitários, graduandos do Bacharelado em Ciências e Tecnologia (BCT), na Escola de Ciências e Tecnologia (ECT), da Universidade Federal do Rio Grande do Norte (UFRN), que cursaram o componente curricular Práticas de Leitura e Escrita II (PLE-II) no semestre 2011.1.

O contexto em que se desenvolveu a pesquisa de mestrado constitui-se de uma Unidade Acadêmica Especializada - a Escola de Ciências e Tecnologia (ECT) -, agregada à Universidade Federal do Rio Grande do Norte (UFRN). A ECT foi criada por meio da Resolução no 012/2008-CONSUNI, de 10 de dezembro de 2008, com um único curso de graduação: o Bacharelado em Ciências e Tecnologia (BCT), podendo, no futuro, sediar outros cursos de graduação e também cursos de pós-graduação.

Academicamente, o BCT representa um marco de transformação no ensino superior da área de ciências exatas e tecnológicas. Isso porque o curso oferece o maior número de vagas entre todos os da UFRN (cerca de 1.120 por ano) e propicia uma formação em dois ciclos (o básico e o subsequente).

Nesse sentido, esse curso favorece uma escolha profissional mais amadurecida e a oportunidade de, em um espaço de cinco anos ou um pouco mais, o graduando obter dois diplomas de nível superior, quais sejam: bacharel em Ciências e Tecnologia e engenheiro de uma das oito engenharias com entrada pelo BCT ou, ainda, bacharel em Física ou em outro curso da área de ciências exatas e da terra.

Na formação básica, além de componentes da área de Matemática, Física, Informática e Química, esses graduandos cursam, obrigatoriamente, 
componentes das áreas de Práticas de Leitura e Escrita (PLE) e de Ciências, Tecnologia e Sociedade (CTS). Essas áreas têm o objetivo geral de oferecer subsídios para uma formação mais humanística a futuros profissionais da área de ciências exatas e tecnológicas.

$\mathrm{O}$ aporte teórico-metodológico que trazemos, neste artigo, ancora-se nas concepções de natureza dialógica da língua(gem) (BAKHTIN, 2009), dos estudos de letramento como prática social (KLEIMAN, 1995; OLIVEIRA; KLEIMAN, 2008), dos estudos sobre o letramento digital (XAVIER, 2002, 2007; COSCARELLI; RIBEIRO, 2007).

\section{Escrita, letramentos, letramento digital}

A escrita é uma tecnologia que surge para resolver problemas do cotidiano e exerce várias funções sociais na história da humanidade. Uma delas é preservar informações no espaço e no tempo (CHARTIER, R., 1998, 2002, 2007; CHARTIER, A., 2007; SILVA, 2013). Essa tecnologia exerce um papel importante na vida de cada um dos participantes da sociedade grafocêntrica. Seja por prazer, por obrigação ou por outro motivo qualquer, as pessoas escrevem e assim se inscrevem no mundo.

Ao longo dos anos, diferentes povos, em diferentes épocas e lugares, marcaram árvores, pedras, conchas e foram criando símbolos (pictogramas). Nossos antepassados já liam os indícios da natureza e tentavam reproduzir seu pensamento em grandes suportes (pedras e rochas), visto que não se podia (nem se devia) contar apenas com a memória. Por meio de desenhos ou pinturas rupestres, era possível registrar o cotidiano, divulgar ideias, desejos, necessidades.

De fato, o papel que a linguagem - em especial, a escrita - exerce na vida da humanidade é inegável. Pela linguagem, o homem atua no mundo. É ela que permeia o saber e as formas de saber, o pensamento e as formas de pensar, a comunicação e os modos de comunicar, o ato e os modos de agir. Ela move o homem e é movimentada por ele, ou seja, tanto é produto quanto é produção cultural, nascida por força das práticas sociais (SILVA, 2013, p. 34). 
Seja oral, seja escrita, a linguagem se constitui e é constituída por práticas sociais. É por ela que ressignificamos saberes, relações sociais e identidades. Logo, por compreendermos a palavra como um fio condutor entre um indivíduo e os outros, ancoramos este estudo em alguns aportes teóricos fundamentais. O primeiro deles é a concepção dialógica de língua(gem) bakhtiniana (BAKHTIN, 2009).

Nesse raciocínio dialógico,

Toda a essência da apreensão apreciativa da enunciação de outrem, tudo o que pode ser ideologicamente significativo tem sua expressão no discurso interior. Aquele que apreende a enunciação de outrem não é um ser mudo, privado da palavra, mas ao contrário um ser de palavras interiores. [...] A palavra vai à palavra (BAKHTIN, 2009, p. 153-154).

Desse modo, é no quadro do discurso interior que, segundo Bakhtin, efetua-se a apreensão da enunciação de outrem, sua compreensão e sua apreciação, ou seja, a orientação ativa do falante. Esse procedimento se realiza em dois planos: de um lado, a enunciação de outrem é recolocada no contexto de comentário efetivo, e de outro, prepara-se a réplica interior [grifos do autor]. São, espontaneamente, fundidos na unidade da apreensão e não são isoláveis senão de modo abstrato. Assim, o discurso citado e o contexto narrativo unem-se por relações dinâmicas, complexas, tensas.

Quanto aos estudos do letramento, na literatura brasileira, a palavra letramento não aparece ainda na maioria dos dicionários, pois há certa imprecisão quanto à diversidade de olhares em relação ao fenômeno "letramento(s)". No Brasil, Mary Kato (1986) foi a primeira pesquisadora a citar o termo "letramento", o qual se originou do termo literacy que já tinha sido anunciado por Heath, em 1983 e por Street, em 1984.

A partir desses pesquisadores, o conceito de letramento assume caráter mais social e ideológico, e os debates que objetivam a compreensão do que institui o letramento e a importância que a ele é atribuída, ganham espaço nos diferentes contextos sociais. Além disso, esses debates envolvem várias contribuições teóricas que surgem da Sociologia, da Psicologia, da História, da 
Etnografia, da Pedagogia. Dentre essas abordagens, temos interesse pelas que são ancoradas pela Antropologia, Etnografia e Linguística Aplicada.

Tfouni (1995) foi uma das primeiras a utilizar e a definir o termo letramento, posteriormente ela o conceitua em confronto com a alfabetização: "[...] enquanto a alfabetização ocupa-se da aquisição da escrita por um indivíduo, ou grupo de indivíduos, o letramento focaliza os aspectos sóciohistóricos da aquisição de um sistema escrito por uma sociedade" (TFOUNI, 1995, p. 20).

Soares (1998) também o define: letramento é estado ou condição de indivíduos ou de grupos sociais de sociedades letradas que exercem efetivamente as práticas sociais de leitura e de escrita participa competentemente de eventos de letramento. Soares (1998), apesar de reconhecer letramentos, no plural, dedica-se a abordar o letramento que se restringe à esfera escolar [destaque nosso].

Por letramentos, aqui nesse estudo, assumimos o que declara Kleiman (2005, p. 21):

O letramento abrange os processos de desenvolvimento e o uso dos sistemas da escrita nas sociedades, ou seja, o desenvolvimento histórico da escrita resultando outras mudanças sociais e tecnológicas, como a alfabetização universal, a democratização do ensino, o acesso a fontes aparentemente ilimitadas de papel, o surgimento da Internet.

De modo geral, essas concepções partem do princípio de que o conceito de letramento(s) refere-se às múltiplas práticas sociais mediadas pela escrita que o indivíduo desenvolve e que as coloca em ação de acordo com o contexto, para atingir um determinado fim socialmente previsto (KLEIMAN, 1995; OLIVEIRA; KLEIMAN, 2008; TINOCO, 2008).

Barton (1998 apud XAVIER, 2007) também já tinha defendido a existência paralela de vários tipos de letramento. Segundo esse autor:

Letramento não é o mesmo em todos os contextos; ao contrário, há diferentes Letramentos. A noção de diferentes letramentos tem vários sentidos: por exemplo, práticas que envolvem variadas mídias e sistemas simbólicos, tais como um filme ou computador, podem ser 
considerados diferentes letramentos, como letramento fílmico e letramento computacional (computer literacy).

Dessa forma, o letramento digital seria mais um tipo e não um novo paradigma de letramento imposto à sociedade contemporânea pelas inovações tecnológicas. Nesta vasta gama de práticas sociais de leitura e de escrita, o conceito de letramento vem sendo adjetivado com o propósito de melhor delimitar cada uma de suas distinções. É possível, portanto, encontrar estudos sobre letramento literário, matemático, jurídico, familiar, religioso. Tal diversidade, portanto, vem sendo objeto de estudos como os multiletramentos na escola desenvolvidos por Rojo (2012).

Xavier (2007) anunciou que o domínio do letramento alfabético pelo indivíduo é a principal condição para a apropriação do letramento digital. Isso indica que um cidadão só pode utilizar com autonomia as vantagens da era digital à sua necessidade se antes tiver aprendido a ler e a escrever, isto é, se tiver dominado o sistema alfabético, as convenções ortográficas que orientam o funcionamento da modalidade escrita de uma língua. Em suma, apenas o letrado alfabético tem a qualificação para se apropriar totalmente do letramento digital.

Considerando esse raciocínio, observamos que algumas pesquisas sobre as práticas de leitura e escrita no meio virtual são recentes. Por essa razão, neste artigo, ancoramo-nos em Xavier (2002, 2007), Coscarelli e Ribeiro (2007). Esses estudiosos somando a outros pesquisadores desenvolvem, desde as últimas décadas, algumas pesquisas acerca da leitura e escrita em ambiente virtual, a forma de conceber o tempo, o espaço e os relacionamentos. Nessas pesquisas, eles assumem que o hipertexto, os textos digitais, as novas formas de ler e de escrever invadiram de modo irreversível a nossa vida.

Inicialmente, Xavier $(2007$, p. 2$)$ afirma que:

O Letramento digital implica realizar práticas de leitura e escrita diferentes das formas tradicionais de letramento e alfabetização. Ser letrado digital pressupõe assumir mudanças nos modos de ler e escrever os códigos e sinais verbais e não-verbais, como imagens e desenhos, se compararmos às formas de leitura e escrita feitas no 
livro, até porque o suporte sobre o qual estão os textos digitais é a tela, também digital.

Nesse trecho, percebemos com clareza as mudanças que o computador e a internet trouxeram para colaborar com a vida das pessoas e também ressignificar antigas práticas de ler e escrever. O letrado digital pode assumir com autonomia determinadas tarefas, via online, nas empresas, nos bancos, nas escolas, nas ruas, nos diferentes lares e lugares. Esses cidadãos são capazes de resolver serviços bancários, evitando enormes filas; de divulgar, comprar e vender produtos em diversos lugares no Brasil e no mundo. Além de se manterem informados de acontecimentos quase no mesmo instante em que os fatos ocorrem.

Coscarelli e Ribeiro (2007, p. 9), por sua vez, asseguram: "[...] Letramento digital é o nome que damos, então, à ampliação do leque de possibilidades de contato com a escrita também em ambiente digital (tanto para ler quanto para escrever)". No entanto, é isso que notamos em nosso cotidiano, links e mais links. Infinidade de textos abertos nesse ambiente que nos possibilitam aprimorar práticas de leitura e escrita.

Nesse raciocínio, observamos também que a cada dia, surgem novas invenções móveis (celular, smartphone, tablet, por exemplo) que ocupam espaço e, em nossa sociedade, nada permanece como está. Milhões de usuários da internet acessam todos os dias vários hipertextos de diferentes assuntos e para os mais diversos fins, ou seja: leem, escrevem, pesquisam, consultam sites, comunicam-se, interagem através do mundo virtual com velocidade surpreendente.

Considerando esse contexto, com o passar dos anos, mudam-se os recursos tecnológicos, os suportes, as ferramentas para escrever e ler, as práticas de leitura e escrita. Por essa razão:

[...] a prática do leitor fornece subsídios para que os produtores de material escrito e/ou de dispositivos para leitura possam repensar, reprojetar e reinventar matérias e recursos, de acordo com a demanda constante do leitor, que busca conforto, eficiência, portabilidade e compreensibilidade. E o leitor vai se conformando ao 
objeto de ler, num ciclo retroalimentado e retroalimentador (COSCARELLI; RIBEIRO, 2007 p. 126-127).

E mais, ao analisar as práticas de ler textos impressos e digitais nos textos desses graduandos colaboradores, o modo como se constrói o diálogo entre os participantes no gênero da ordem do argumentar - 0 artigo de opinião - , constatamos que letramentos envolvem muito mais do que o simples acesso aos códigos do sistema da língua escrita. Isso porque, na visão de nossos colaboradores, com o surgimento do computador e da internet, eles leem e escrevem uma diversidade infinita de textos no papel e na tela.

Por fim, é visível que as técnicas da escrita, nos dias atuais, são variadas e ainda as pessoas fazem uso de outras tecnologias, sejam elas "analógicas", ou "digitais". Por mais que se tenha receio sobre os novos modos de ler e de escrever, por nos deparar quase sempre com pessoas angustiadas que enxergam o computador com certa indiferença. Ressaltamos, portanto, que essa nova máquina não deve ser vista nem com deslumbramento nem como uma ameaça em detrimento da cultura de papel.

\section{Análise}

A ideia pioneira e inovadora que originou na criação de e-book (ou livro eletrônico) foi de Michael Hart, nos Estados Unidos, a qual data de 1971, que decidiu criar com o armazenamento em computador, a recuperação e exploração dos textos disponíveis nas bibliotecas.

Essa evolução resultou no primeiro livro eletrônico, uma cópia da declaração de Independência que, posteriormente, evoluiu na invenção da imprensa por Gutenberg. Atualmente, esses dispositivos eletrônicos contam com mais de 20.000 textos livres e mais de 100.000 livros.

Esse fato é lembrado em um dos textos escritos pelos alunos de BCT que discorre sobre sua escolha desses dispositivos de leitura na era digital, entre muitos outros que poderíamos trazer para a análise. 
Estamos na era digital e tudo está se adaptando a esses novos tempos, com os livros não pode ser diferente. Hoje estamos em um prédio moderno, com muita tecnologia. Terminais de acesso à internet nos corredores, elevadores, laboratórios com toda tecnologia necessária. Então precisamos de uma biblioteca que ande de acordo com essas inovações $(\mathrm{C} 1)^{2}$.

Encontramos nesse trecho alguns traços relevantes os quais explicitam a preferência desse colaborador pelo formato digital, reportando-se ao contexto sócio-histórico: "estamos na era digital e tudo está se adaptando a esses novos tempos, com os livros não pode ser diferente...". Alerta-nos para a necessidade urgente de adaptação às mudanças sociais e tecnológicas. Nesse trecho, vemos também que o colaborador faz o mapeamento positivo da ECT: "[...] hoje estamos em um prédio moderno, com muita tecnologia".

Essa declaração, de certa forma, sinaliza-nos a infraestrutura da ECT: uma escola inovadora com três andares, um auditório amplo por andar, elevador, salas informatizadas, laboratórios de química, de informática, computadores com acesso à internet nos corredores, conforme aponta o colaborador em seu artigo de opinião.

Ainda sobre os e-books, dados estatísticos também realçam avanço significativo da leitura nesses dispositivos. Em 2010, o crescimento do mercado global de e-books foi bastante elevado de mais de $200 \%$. Correspondeu a $9 \%$, em 2008 foi $1 \%$ e, em 2009, 3\%. Tais dados representam um volume de negócio de cerca de 900 milhões de dólares. Esta tendência é alimentada pelas vendas nos Estados Unidos, com uma quota de $80 \%$ de um mercado onde a Europa Ocidental representa apenas $10 \%$ e resto do mundo outros $10 \%$. Nesse mercado, um dos setores de maior crescimento significativo foi o de livros para crianças e jovens adultos.

Contrários a essa inovação encontram-se os editores de livros convencionais e outros sujeitos que não aceitam que o livro eletrônico hoje é realidade. Hoje os leitores do século $X X$, sem noção do conceito do livro

\footnotetext{
2 Optamos neste estudo por usar C1 - colaborador 1 ; C2 - colaborador 2 e assim sucessivamente, para preservar a identidade de nossos colaboradores. Mas na dissertação, utilizamos pseudônimos para nomeá-los.
} 
eletrônico, estão gradualmente expostos a esse fenômeno eletrônico. Viajantes leem livros eletrônicos em laptops, computadores de mão ou telefones celulares.

Aliando-se aos editores bibliófilos, há um grupo de graduandos que preferem a leitura no formato impresso. Vejamos o que eles dizem em dois trechos destacados:

Os livros impressos carregam valores culturais, é através de muitos deles que o conhecimento e histórias do passado foram preservados (C2).

Os livros impressos permitem-nos ao longo de sua leitura, um sentimento de cumplicidade (...) nos animamos e vivenciamos os fatos descritos... (C3).

$\mathrm{Na}$ Europa, salvo raras exceções, os e-books são vistos pelos grupos editoriais mais como uma ameaça do que como uma oportunidade. Unindo-se a esses grupos, encontram-se alguns graduandos/leitores de livros convencionais. Esses também não aceitam que o livro eletrônico hoje é realidade, quer eles queiram ou não. Resta-Ihes, como fuga, ignorá-lo e ser alheios a tal fato.

Por último, destacamos o resultado revelado na leitura dos textos supracitados sobre a disputa de gosto e de espaço de livro impresso e livro digital. E mais ainda, trazemos um gráfico ${ }^{3}$ abaixo, que sintetiza a preferência pelo tipo de publicação: impressa ou digital sinalizada pelos colaboradores.

\footnotetext{
${ }^{3}$ Os primeiros resultados desse gráfico foram apresentados no pôster "Livro digital e/ou livro impresso? a polêmica que se constrói na vida e nos textos argumentativos de graduandos de ciências e tecnologia", no Simpósio Internacional de Estudos de Gêneros Textuais (SIGET) em Natal/RN, 2011.
} 
Gráfico 1 - Preferência pelo tipo de publicação sinalizada pelos colaboradores

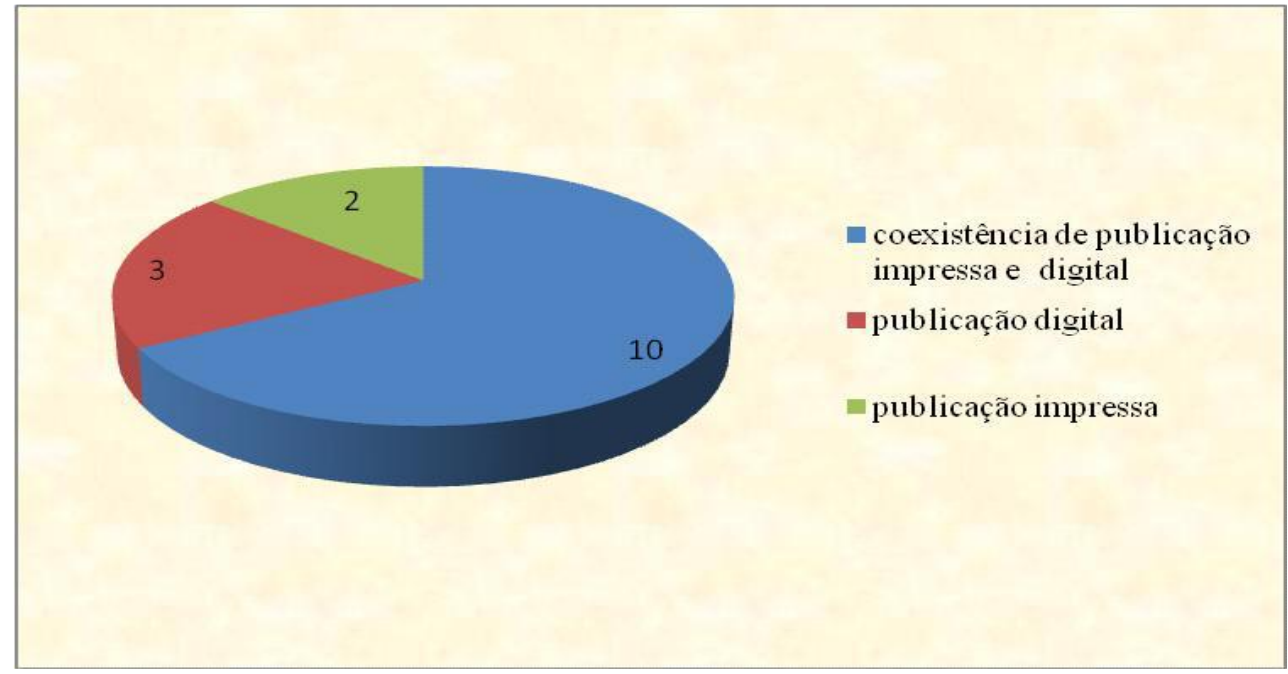

Fonte: a autora.

$\mathrm{Na}$ análise desse gráfico, constatamos alguns dados interessantes e contraditórios. Em dados percentuais: 66,66\%, dez dos colaboradores, optam pela coexistência de livros impressos e digitais; $20 \%$, três deles apenas pela publicação de livro digital; $13,33 \%$, que equivalem a dois graduandos, optam pela publicação de livro impresso.

Considerando aqueles que apontam a coexistência, percebemos que alguns deles na entrevista, optam pelo livro impresso; no artigo de opinião e no questionário, optam pela publicação impressa e pela digital. No cruzamento dos dados, observamos que, apesar dessas ideias contraditórias, no geral, eles dizem que se consideram "leitores e escreventes de publicação impressa e de digital".

Os resultados apresentados nesse gráfico vão de encontro às expectativas preliminares, pois pensávamos que nossos colaboradores iam declarar em seus textos a opção pelo formato digital. O que não ocorreu porque a maioria deles escolheu o formato impresso, mas não descartou 0 digital.

Assim, ao analisar esse gráfico, vimos que é possível sim a coexistência de livros impressos e livros digitais. Para melhor ilustrar este fato, vejamos os trechos a seguir. 
Os livros impressos trazem uma tradição cultural muito forte (...). Os livros digitais trouxeram consigo a comodidade e praticidade de ler livros de qualquer gênero... Em suma ... São de total importância para comportar uma biblioteca, já que vai unir a praticidade do livro digital juntamente com a qualidade da tradição impressa. (C4)

Conciliando a leitura digital e impressa temos muito a ganhar atendendo aqueles que ainda são resistentes as tecnologias e aos que gostam de se manter conectado...(C5)

[...] muitas pessoas gostam do livro impresso... Talvez nas bibliotecas por questão de praticidade, as pessoas comecem a usar mais o digital [...] Mas o impresso continua. (C6)

Nesses trechos, percebemos primeiro que, para o colaborador 4, a leitura institui-se a partir de uma relação íntima e física entre o leitor e o objeto de leitura: o livro. Em seguida, ele menciona os modos de aquisição e a presença de livros na biblioteca, em que são postos aspectos ligados à materialidade do livro impresso.

Nesse sentido, a leitura requer, obrigatoriamente, um espaço determinado onde ele é usufruído. Nesse aspecto, a aquisição do livro impresso aparece em desvantagem ao livro digital pela "praticidade" de este ocupar menos espaço físico.

Logo, ainda é a melhor solução a coexistência de papel e de tela numa biblioteca, pois, segundo o colaborador 5, atenderá a preferência tanto de bibliófilos quanto de tecnófilos: "[...] conciliando a leitura digital e impressa temos muito a ganhar $[\ldots]^{\prime \prime}$.

Assim, não vale a pena investir na onda atual sobre o livro de papel que vem sendo movida por algumas pessoas ansiosas diante da possibilidade de um suposto desaparecimento, pois, conforme o colaborador 6: "o [livro] impresso continua". Ou seja, é possível sim o livro de papel dividir o gosto pessoal e o mesmo espaço com o livro eletrônico, estabelecendo assim, com clareza, o continuum defendido por Lévy (1993).

A polêmica sobre o que dizem as pessoas no tocante à preferência entre livro no papel ou na tela ainda continuará por muito tempo. Isso porque alguns autores preferem apenas a versão online, pois não querem que seu livro seja copiado. Outros já preferem apenas a versão de livro digital, até pelo custo mais baixo de produção. 
Por esse motivo, resta-nos pensar sobre o dizem os graduandos do BCT:

[...] sejam qualquer leitor, os que preferem livros impressos ou $e$ books o importante é estar gostando da leitura e sentir que a mensagem do texto ou livro esteja sendo transmitida [...].

E mais:

[...] o que importa é a qualidade de informação (...) o conteúdo... os usuários... A biblioteca da nossa Escola deve atender e agradar a todos que constitui a mesma, oferecendo a qualidade da tradição impressa e as vantagens da digitalização.

Considerando as declarações feitas em seus textos, os graduandos do BCT propagam a ideia de coexistência de livros impressos e digitais para organização do acervo da biblioteca setorial da ECT é a melhor escolha. Isso pode ser visível no registro de outro graduando: "[...] a escola deve 'agregar' o que o próprio nome do curso tem... Ciência com livros impressos... Tecnologia [com] os livros digitais que aparecem para facilitar o acesso a obras muitas vezes caras e raras".

Com essa declaração fica o recado para os editores de como tornar viável uma editora com livros digitais. Esse é um problema que os editores precisam se desdobrar para resolver, pois não existe resposta pronta. Os autores também precisam buscar, urgentemente, novas possibilidades de divulgação de seus trabalhos, via online, com reconhecimento dos diretos autorais de cada um deles. E mais, o que existem são ideias, especulações, pistas sobre o caminho e sobre os obstáculos. Para acompanhar, portanto, todo esse avanço tecnológico, o mundo editorial precisa renascer.

Não resta dúvida de que a invenção que Gutenberg fez com seus tipos móveis mudou o mundo, não pela técnica em si, mas porque essa descoberta foi capaz de reduzir drasticamente os custos do acesso ao conhecimento e abriu as portas para novas ideias que antes estavam isoladas e fragmentadas, subjacentes do conhecimento clássico. 


\section{Considerações finais}

Analisando a concepção de práticas de leitura e escrita em algumas declarações dos graduandos em Ciências e Tecnologia da UFRN, chegamos a alguns resultados satisfatórios. Isso porque nos questionamentos iniciais, o que nos inquietava sobre a polêmica que se constituía nos argumentos dos graduandos, especificamente, se era possível a coexistência de livros impressos e livros digitais, foi revelado nos textos por eles produzidos, bem como se 0 formato impresso resistiria (ou não) às novas tecnologias. Percebemos ainda, com essa análise, que é falsa a ideia de que os e-books suplantarão os livros impressos (pelos menos por enquanto).

Fica evidente aqui que nossos alunos leem e escrevem, tanto em formato impresso quanto em meio digital. De fato, o que se constata entre os colaboradores desta pesquisa são as múltiplas práticas de leituras e de modos de ler e escrever. Afinal, as práticas de leitura estão em todas as nossas ações, seja quando pegamos um livro de Matemática na biblioteca para estudar para prova, seja quando lemos Erasmo de Roterdã para pura fruição, seja quando escrevemos um e-mail solicitando esclarecimentos a um professor ou a um colega de turma. Enfim, cabe-nos enxergar toda essa pluralidade de práticas de leitura e escrita, de acervos e de motivos para ler e escrever.

Percebe-se, claramente, que as práticas de leitura e escrita vão além das exigências das atividades escolares e/ou acadêmicas, e provar que essas práticas estão presentes em nosso cotidiano em todas as esferas sociais de que participamos pode orientar ações mais compatíveis e mais eficazes para a ampliação de letramentos dos graduandos em questão.

Ao contrário do que se esperava, a virada digital não acaba com os livros impressos, mas haverá espaço tanto para o livro impresso quanto para o livro digital. Sendo assim, a implantação das novas tecnologias na educação faz com que as pessoas leiam e escrevam mais, de forma diversificada. Negando, pois, a concepção de leitura e escrita numa visão elitista, advinda do senso comum. 
Além disso, o livro digital tem custos de produção menores e nenhum custo de armazenamento. Esse permite 0 uso de alguns recursos que 0 impresso não permite com tanta facilidade ou com tão baixo custo, como interatividade, fotografias coloridas em todas as páginas. Entretanto, a escolha por um ou outro formato depende do seu objetivo e da sua estratégia. É possível fazer uso das duas versões, um livro online, um livro de papel, desde que esse ou aquele, facilite o acesso do leitor à informação.

A coexistência ainda é a melhor solução. Os livros impressos não desaparecerão. Eles conseguirão, sim, dividir o mesmo espaço com os livros digitais. E a biblioteca eletrônica sem muros não é mais promessa do futuro, já é realidade. Resta-nos conciliar sua materialidade na preservação das formas sucessivas da cultura escrita conservadora, mas também é necessário um espaço para as formas inovadoras de escrita digitalizada.

Em geral, pelas declarações dos graduandos aqui reveladas, entendemos que nem o livro impresso, nem tampouco o livro digital predomina, mas que é possível sim a coexistência de ambos, ou seja, os livros impressos podem dividir o mesmo espaço com os livros digitais, por muito tempo.

\section{Referências}

BAKHTIN. Mikhail. Marxismo e filosofia da linguagem. 7. ed. São Paulo: Hucitec, 2009.

CHARTIER, Anne-Marie. Práticas de leitura e escrita - história e atualidade. Belo Horizonte: Ceale/Autêntica, 2007.

CHARTIER, Roger. Os desafios da escrita. São Paulo: Ed. UNESP, 2002.

CHARTIER, Roger. $A$ aventura do livro: do leitor ao navegador. São Paulo: Ed. UNESP, Imprensa Oficial do Estado, 1998.

COSCARELLI, C.V.; RIBEIRO, A.E.R.(Org.). Letramento digital: aspectos sociais e possibilidades pedagógicas Belo Horizonte: Ceale/Autêntica, 2007.

KATO, Mary. No mundo da escrita: uma perspectiva psicolinguística. São Paulo: Ática, 1986. 
KLEIMAN, Angela B. Os significados do letramento: uma nova perspectiva sobre a prática social da escrita. Campinas: Mercado de Letras, 1995.

KLEIMAN, Angela B. Preciso "ensinar" o letramento? Não basta escrever a ler e a escrever? In: KLEIMAN, Angela B. (Org.). Linguagem e letramento em foco: linguagem nas séries iniciais. Cefiel/IEL/Unicamp, 2005.

LÉVY, Pierre. As tecnologias da inteligência. O futuro do pensamento na era da informática. Tradução Carlos Irineu da Costa. Rio de Janeiro: Editora 34, 1993.

OLIVEIRA, Maria do Socorro.; KLEIMAN, Ângela Bustos(Org.). Letramentos múltiplos: agentes práticas e representações. Natal/RN: EDUFRN, 2008.

ROJO, R. Multi-letramento na escola. São Paulo: Parábola, 2012.

TINOCO, G. M. A. de M. Projetos de letramento: ação e formação de professores de língua materna. 2008. Tese (Doutorado em Linguística Aplicada) - Instituto de Estudos da Linguagem - IEL, UNICAMP, Campinas.

XAVIER, Antonio C. dos Santos. Letramento Digital e Ensino. 2007. Disponível em: https://www.ufpe.br/nehte/artigos/Letramento\%20digital\%20e\% 20ensino.pdf >. Acesso em: 14 maio 2011.

XAVIER, Antonio C. S. O Hipertexto na sociedade da informação: a constituição do modo de enunciação digital. 2002. Tese (Doutorado em Linguistica) Instituto de Estudos da Linguagem, Unicamp, Campinas, 2002.

SILVA, Maria da Guia. O leitor universitário e a construção das práticas de ler e escrever textos impressos e digitais. 2013. 155 f. Dissertação (Mestrado em Estudos da Linguagem) - Universidade Federal do Rio Grande do Norte. Natal, 2013.

SOARES, Magda. Letramento: um tema em três gêneros. Belo Horizonte: Autêntica, 1998.

TFOUNI, Leda Verdiani. Letramento e Alfabetização. São Paulo: Cortez, 1995. 